\title{
Editorial
}

\section{Número Especial: O Centenário de Guerreiro Ramos}

\author{
Fernando G. Tenório ${ }^{1}$ \\ Fundação Getulio Vargas / Escola Brasileira de Administração Pública e de Empresas, Rio de janeiro - RJ, Brasil
}

$\mathrm{O}$ esquecimento parece fazer parte da natureza humana ou, propositalmente, esquecemos certos fatos para que situações passadas não voltem a perturbar o nosso cotidiano. Porém, se considerarmos que a cultura, o conhecimento que adquirimos integram nosso mundo, provavelmente certas epistemes marcam ou até redefinem a nossa maneira de pensar. Desse modo, determinados produtores de conhecimento têm essa faculdade, o dom, o talento de demarcar e/ou remarcar com a sua sapiência o caminhar cognitivo de outros. Assim, para que o esquecimento seja expungido, este número especial do Cadernos EBAPE.BR retoma, no centenário de Alberto Guerreiro Ramos, pegadas que ele deixou ao longo da sua profícua produção acadêmica e ativismo político em prol de uma sociedade mais justa. Portanto a coletânea de artigos que compõem este número especial pretende repor parte do legado de um sociólogo que deixou marcas e traços não só na academia brasileira como também por onde passou, expondo o seu conhecimento sobre as realidades e propondo soluções às contradições promovidas por elas.

É preciso salientar que a dimensão da tarefa de discutir ou rediscutir a obra de Guerreiro Ramos não é passível de ser mensurada, uma vez que o conteúdo por ele produzido induz seus leitores e/ou pesquisadores a múltiplas possibilidades, dada a polifonia de seus escritos - não circunscritos às ciências sociais: vão da estética à política. Portanto o presente periódico Cadernos EBAPE.BR não esgota o ensejo de novas iniciativas não só no que diz respeito a interpretações do acervo deixado pelo Prof. Guerreiro, mas, também, apresenta oportunidades de dar continuidade ao sendeiro por ele aberto.

Este número especial, originado no Seminário Internacional Guerreiro Ramos: "O legado de uma dupla cidadania acadêmica" - realizado pela Diretoria Internacional (DINT) da Fundação Getulio Vargas (FGV) em 15 de outubro de 2014 - reflete não somente o significado de sua produção acadêmica, como também a sua ação parlamentar e sua proposta de uma pós-graduação direcionada ao desenvolvimento nacional - como foi o caso da sua proposição à Universidade Federal de Santa Catarina (UFSC) por meio do seu Programa de Pós-Graduação em Administração. Observe-se que no subtítulo do seminário, "O legado de uma dupla cidadania acadêmica", reconhece-se que a atividade de ensino e pesquisa do Prof. Guerreiro não ficou restrita ao espaço geográfico brasileiro, estendeu-se, também, a outros contextos nacionais, como, por exemplo, os Estados Unidos da América (EUA), quando atuou na Universidade do Sul da Califórnia (USC), instituição que também apoiou a organização implementação desse evento.

Assim, este número especial do Cadernos EBAPE.BR procura refletir a polifonia acima indicada, a começar pelo artigo do Prof. João Marcelo E. Maia, História dos intelectuais no Terceiro Mundo: reflexões a partir do caso de Guerreiro Ramos. As reflexões do Prof. João Marcelo poderão ser ampliadas pelo artigo do Prof. Gaylord George Candler, 'Assimilação crítica' and research on the perifery. $O$ conceito de "comunidade humana universal" na obra de Guerreiro Ramos, do Prof. Elio Chaves Flores, alonga ainda mais as

\footnotetext{
DOI: http://dx.doi.org/10.1590/1679-395153446

${ }^{1}$ Bolsista Produtividade CNPq; Pós-doutor em Administração Pública, IGOP/Universitat Autónoma de Barcelona (UAB); Professor Titular da Escola Brasileira de Administração Pública e de Empresas da Fundação Getulio Vargas; Coordenador do Programa de Estudos em Gestão Social (PEGS). Editor-Chefe do Cadernos EBAPE.BR. Endereço: Praia de Botafogo, $190-5^{\circ}$ andar - Botafogo, CEP 22250-900, Rio de Janeiro, RJ - Brasil. E-mail: fernando.tenorio@fgv.br
} 
reflexões teóricas do "velho Guerreiro", como carinhosamente nos referíamos a ele na EBAP ainda sem o "e" de Empresas.

A continuidade da análise dos conceitos trabalhados pelo Prof. Guerreiro poderá ser observada ainda no artigo de Ariston Azevedo e Renata Ovenhausen Albernaz, A razão d'A Nova Ciência das Organizações. Já a estética se sobressai no texto do Prof. Marcos Chor Maio, Cor, intelectuais e nação na sociologia de Guerreiro Ramos. O papel político e parlamentar do nosso homenageado é explorado pelo Prof. Américo Freire em $O$ social-trabalhismo do deputado federal Guerreiro Ramos. A implementação do pensamento do "sociólogo Guerreiro"2 na Universidade Federal de Santa Catarina (UFSC) foi narrada pelo Prof. José Francisco Salm em Pressupostos, Fundamentos Teóricos e Legado do Curso de Mestrado em Planejamento Governamental Desenvolvido por Alberto Guerreiro Ramos. Concluímos esta edição com o relato do Seminário Internacional Guerreiro Ramos 2014 - O Legado de uma Dupla Cidadania Acadêmica, editado pelo Prof. Ariston Azevedo e Prof. Américo Freire.

Para o periódico Cadernos EBAPE.BR é uma honra ter a oportunidade de publicar um número especial no centenário do Prof. Guerreiro não só pela sua grandeza intelectual, mas, também, pelo fato de tal publicação ocorrer no momento em que este periódico, que era classificado como B1, passa a A2 no estrato de classificação na área de Administração, Ciências Contábeis e Turismo em recente avaliação quadrienal (2013-2016) da CAPES. Desse modo, a equipe editorial do Cadernos EBAPE.BR, Prof. Fernando G. Tenório (Editor-Chefe), Fabiana Braga Leal (Assistente Editorial) e Anderson Ricci (Auxiliar Editorial) agradecem o apoio da EBAPE/FGV, o envolvimento e a colaboração de todos os autores, pareceristas, leitores e profissionais que atuam na revista, fazendo desta uma fonte de conhecimento e debates interdisciplinares no campo da gestão.

Boa leitura!

Fernando G. Tenório

Editor-Chefe

${ }^{2}$ No dizer de Lucia Lippe (In: OLIVEIRA, L. L. A Sociologia do Guerreiro. Rio de Janeiro: Editora UFRJ, 1995). 